\title{
Style Guide for Arctic Anthropology
}

Arctic Anthropology is an international journal devoted to the study of northern cultures and peoples, past and present, in both the Old and New Worlds. The journal publishes papers that cover the disciplines of archaeology, ethnology, ethnohistory, linguistics, human biology, and related fields, as well as interdisciplinary papers that include a human dimension. Papers submitted should not have been published previously, nor should they be under consideration elsewhere.

\section{Writing Style}

For the most part, Arctic Anthropology encourages authors to use the conventions of a formal academic writing style. Since the journal publishes papers from a variety of academic disciplines, authors are encouraged to write with a broad readership in mind, avoiding jargon. If a particular paper calls for a more informal writing style, the author should consult with the editor before submission.

\section{Manuscript Submission}

All manuscripts must be word processed and in electronic format. Double-space all sections of the manuscript: the abstract, main text (including quotations), tables, endnotes, acknowledgments, references cited, list of tables with their captions, and list of figures with their captions. Margins should be at least one inch on all sides. Pages should be numbered consecutively. Arctic Anthropology uses the conventions of American Anthropologist, with some exceptions identified below. Please consult the style guide when preparing your manuscript.

Arctic Anthropology is edited and produced electronically. Papers are edited using Microsoft Word and will be disseminated back to authors in Word format (either *.doc or *.docx). Manuscripts can be submitted in other formats created using other word processing software (e.g., Google Docs, WordPerfect, AbiWord, etc.) but will be translated into Word format in the editorial process. Do not submit manuscripts in Adobe PDF format.
If the manuscript includes tables or figures, submit them as pages and files distinct from the text. Be sure to include a list of captions for tables and figures, appended to the end of the paper. Tables will be typeset (see instructions below). It is strongly suggested that authors use the table functions in Microsoft Word to create their tables rather than using tabs or Microsoft Excel. Please consult the instructions that follow regarding preparation of figures.

\section{Manuscript Format}

\section{Title Page and Abstract}

The title of the paper should appear at the top of the title page, centered. Skip three lines and type the name of the author(s), skip three lines and type an abstract of no more than 150 words. The abstract must be double-spaced paragraph, left justified. Begin paragraph with the heading "Abstract" italicized and followed by a period.

Skip three lines after the abstract and type the author's name(s) and follow each name with the author's institutional affiliation and full mailing address including a building address (not just a P.O. Box) and zip code or postal code. Please provide a current email address for each author as well. Names should appear in order of seniority, with the lead author's name appearing first.

\section{Text}

Begin the text of the paper on a new page. Do not use hard returns within paragraphs, and do not manually hyphenate words at line breaks. The first paragraph following a title or subheading is not indented. The content of the text must be double spaced.

\section{Subheadings}

Most articles are better organized if subdivided into major sections, with appropriate subsections where necessary. However, too many levels of sub- 
division can be as confusing as too few. In most cases, three or fewer levels are adequate.

To indicate the relative importance of subheadings, they should be ordered as shown below. Always use two returns above and below subheadings and be sure the levels are consistent throughout the manuscript.

$\begin{array}{ll}\text { Centered, Initial Capitals, Bold } & 1 \\ \text { Initial Capitals, Bold } & 2 \\ \text { Centered, Initial Capitals, Italics } & 3 \\ \text { Initial Capitals, Italics } & 4 \\ \text { Initial Capitals } & 5 \\ \text { Initial Capitals } & 6\end{array}$

\section{Citations}

Citations within the text should follow the style specified by American Anthropologist. Every citation must include the author's name (unless the name is in the passage to which the citation applies), date of publication, and, when appropriate, page number(s). When a citation involves multiple works, authors' names should be listed in alphabetical, not chronological order. All citations must have related entries in the "References Cited" section of the paper. Citation of a paper delivered at a conference but never published and not available in a repository is discouraged. Please note the use of colons, semicolons, spacing, and organization in the following examples:

Single author: (Jones 1992:60-68)

Coauthors: (McCartney and Savelle 1985)

Three or more authors of the same work: (James et al. 1987)

Multiple works: (Jones 1992; Smith 1989; White 1999). Note the alphabetical order of the works, which are separated using a semicolon.

Multiple works by the same author: (Ingling 1989, 1992, 2001). Note the chronological order of the works, which are separated using a comma.

Multiple works by the same author that have the same date: (Taylor 1977a, 1977b)

Multiple works involving the same lead author: (McCartney 1995:83; McCartney and Savelle 1985). Note that single author works by an author should appear before coauthored or edited works by the same author.

Edited work: (Fitzhugh [ed.] 1975)

Multiple works by the same author, same date, including edited work: (Parker 1992, 2001; Parker [ed.] 1992).
Main citation and related citation: (Maars 1978; see also Alberg 1943)

Publication in press: (Lee, in press)

Conference paper never published: (Jordan, n.d.) - use of unpublished conference papers is discouraged.

Personal communication: (McCartney, personal communication 2002)—do not list in "References Cited" section.

\section{Quotations}

Quotations of forty words or less should be set off with quotation marks and run within the text. Provide the citation (author, date, page) enclosed in parentheses following the closing quotation marks. Quotations of forty words or more should be indented on the right one tab stop (0.5) and followed by the citation enclosed in parentheses (exception to American Anthropologist). Please note use and placement of quotation marks, punctuation, and parentheses in the following examples.

Short quotation: He has pointed out that the Arctic is "a natural laboratory for studying global environmental issues” (Nuttall 1998:8).

\section{Long quotation:}

Now the master of ceremonies puts on his head ring, which consists of a flat strip of cedar bark, to which a long trail of the same material is attached. Again he sings his secret song and goes around the fire four times swinging the rattle, which he holds approximately at the height of his head. During this song people bend their heads down and move on their seats in order to gain a convenient position (Boas 1897:510).

\section{Endnotes}

Use endnotes rather than footnotes. If the manuscript has been accepted for publicaiton, all footnotes will be converted to endnotes. It is stressed that endnotes should be used only when absolutely necessary and be as short and concise as possible. Number the endnotes consecutively throughout the body of the text using superscript cardinal numbers, not letters or other characters. The endnotes must be double-spaced and be placed before the "References Cited" section of the paper. If possible, avoid using the endnote function in Microsoft Word. If endnotes include bibliographic citations, be sure the works cited are listed in "References Cited." 


\section{Tables}

It is recommended that authors use the table functions in Microsoft Word to create tables. Tables should be created in individual files and not embedded into the text, regardless of size. Avoid unnecessary and excessive horizontal and vertical marker lines in tables. Number the tables consecutively as they appear in the text (i.e., label the file for each table as: Author_Table_1, Author _Table_2, etc.)

\section{Table Captions}

Table captions should appear at the top of the first page of a table, flush left. Captions should be brief but accurately reflect the content of the table. A period should follow the number of the table. The word "Table" the table number, and the period should appear as demonstrated below. A list of tables and their captions should be included with the manuscript.

Caption: Table 1. Distribution of artifacts at the Campus site.

\section{Text References to Tables}

All tables must be referred to in the text of the paper. When referring to a specific table, the word "Table" should be spelled out and capitalized.

Mentioned as part of a sentence: "The events in the antisealing campaign are listed in Table 2."

Included in parentheses within or at the end of a sentence: "Quantities of worked caribou antler were recovered from the sleeping platform (Table 3).”

\section{Figures}

Authors must submit illustrations in electronic format as individual files. The preferable formats for raster image (e.g., photographs) submission are TIFF ( ${ }^{*}$.tif), JPEG ( ${ }^{*}$.jpg), or Adobe Photoshop ( ${ }^{*}$.psd). For vector images (e.g., maps, graphs), the preferred formats are Adobe Illustrator (*.ai) and Scalable Vector Graphics ( ${ }^{*}$.svg). Do not submit illustrations in Adobe PDF format ( ${ }^{*}$.pdf), Microsoft Powerpoint ( ${ }^{*}$.ppt), or embedded in Microsoft Word documents. As with table files, the figure files should be labeled as follows: Author_Figure 1, Author Figure 2, etc.

All figures must be mentioned in the text and numbered sequentially in the order in which they are referred to in the paper. Do not include the figure number, caption title, or caption as part of the figure. Rather, list all figure numbers and captions in a separate Word file.

\section{Maps}

Maps must include proper geographic information. This should include a scale, a North arrow, latitude/longitude information, or UTM coordinates when appropriate. In addition, if specific symbols are used in the map, then either a legend or a detailed explanation of the symbols in the figure caption must be included. Also, follow formal conventions for map making, such as labeling the names of bodies of water in italics.

\section{Artifact or Object Drawings or Photographs.}

A scale must be included in drawings or photographs of artifacts or objects, or a reference to the size of the object must appear in the figure caption. If multiple objects are included in a figure, they should be identified sequentially using lower case letters and be of the same scale unless otherwise noted in the figure caption. Avoid using dark or shaded backdrops for artifact photographs because such images may be too dark to print satisfactorily.

\section{Legibility}

Illustrations should be selected with black and white publication in mind. Use simple patterns and fonts when creating maps, graphs, and drawings, and avoid relying on color to make distinctions between symbols. Avoid using shading gradations, as the illustration will not reproduce well. Consider line thickness and font size when creating figures. Line widths should be no less than 0.25 of a stroke ( 0.5 is better) and the minimum of 6 pt. size for fonts. Be aware that some figures will be reduced in size to fit into the journal's printed format, which will reduce the size of both fonts and lines.

For graphic works, a resolution of $600 \mathrm{dpi}$ is preferred to maximize the detail of the illustration for print.

\section{Illustration size}

When preparing original artwork, please keep in mind that illustrations are fit to three different sizes: 1 column quarter page (a maximum width of 3.3 inches [84 mm]), 2 columns (a maximum width of 6.8 inches [173 mm], or landscape or portrait full page (landscape: maximum size 9 inches [229 $\mathrm{mm}$ ] wide by 6.8 inches [172 $\mathrm{mm}$ ] high; portrait: vice versa). If figure size is of key importance to the article, please let the editor know your preferences for size.

Photographs Photographs should be submitted in TIFF (*.tif), JPEG ( *.jpg), or Adobe Photoshop 
( ${ }^{*}$.psd) format and can be in either grayscale or color. However, the latter will be converted to grayscale for printed publications. Photographs should be at a minimum of 300 dpi to ensure quality of the image, though $600 \mathrm{dpi}$ is preferred.

Do not submit original printed photographs; rather, obtain a high-resolution scan of the image for submission if the image is not already in digital format. If scanning photographs or other images, please take care to center and square the item being scanned and use 600 dpi image quality.

\section{Figure Captions and Text References}

Simple Figure Captions. The term "Figure" is always spelled out and capitalized in captions.

Caption: Figure 6. Spirit mask used in the spring ceremony.

Multicomponent Figure Captions. When a figure contains a number of components, such as a series of artifacts, they should be identified in the caption using lower case, italicized letters if possible.

Caption for figure that has multiple components: Figure 4. Lithic specimens from the Ramah Bay quarry site: $a-c$, cores; $d-f$, bifaces; $g$, pick.

Text References to Figures When referring to a specific figure as part of a sentence, the word "Figure" is capitalized and spelled out. When the reference to a specific figure appears in parentheses, the word "Figure" is abbreviated "Fig." (exception to American Anthropologist).

Mention of a specific figure as part of a sentence: The 2001 study area is delineated in Figure 1.

Reference to specific figures using parentheses: Artifacts recovered included slate ulu blades (Fig. 1a-c) and a nephrite drill bit (Fig. 2).

\section{Numbers, Measurements, and Dates}

Use true numeric characters rather than the letters O ("oh") or l ("el"). Numbers one through ten are spelled out in the text unless the number is part of an arithmetic expression or data being reported.

Numbers one through ten: "He received six reindeer in the transaction."

A list of numbers containing numbers larger than ten: "There were 1,090 bone fragments, 500 broken points, and two bone awls. ..."

An arithmetic expression: "a frequency of 1 in $10 \ldots$...

Reporting of data: "at the village 9 out of 17 women sewed."
Measurements and Weights Use numerals and abbreviations for measurements and weights (an exception to American Anthropology). Note that if measurements are given in U.S. customary units or Imperial units, provide a metric conversion in parentheses.

Measurements: $17 \mathrm{~mm}, 1 \mathrm{~m}, 12 \mathrm{~cm}, 1$ in $(25.4 \mathrm{~mm})$ Weights: 2 lbs (0.45 kg), 7 oz (198 g)

Four-digit numbers Use commas in four-digit numbers except for page numbers and calendar years.

Four digit numbers that use commas: "The artifact collection includes 4,598 microblades."

Page numbers: "It can be found on page 5024."

Calendar years: "She was in the field in 1999 and again in 2001."

Fractions Hyphenate fractions when they are used as adjectives or nouns. When using numerals, use full digits instead of symbols (1/3 instead of $1 / 3)$.

Fractions: "a three-quarter length sleeve;" "twothirds of the children"

Dates. Dates mentioned in the manuscript should follow the formats specified below.

Month, day, and year: September 30, 2002 (not

September 30th, 2002)

Month and year: August 2000 (no comma)

Decades: 1970s or the seventies (not 1970's or 70s)

Centuries: 17th century (not seventeenth century). Do not superscript the "th."

Radiometric Dates Radiometric dates of all forms published for the first time must be reported by providing the uncalibrated date, followed by the 1-sigma standard error provided by the lab, followed by with the name of the lab, the sample number, and the nature of the material dated (exception to American Anthropologist). Original radiocarbon dates should be presented as conventional radiocarbon dates. Authors are encouraged to consult the journal Radiocarbon regarding reporting conventions.

Radiometric age first reported: $760 \pm 60$ BP (Beta 1258815, wood)

Calibrated Dates Calibrated dates must be identified with the word "cal." (meaning "calibrated," not "calendar") appearing before the date. The calibrated date should be reported in a calendar age range using "AD" or "BC" The calibration program utilized must be reported in the text of the paper, in a table, or in an endnote, and authors must note whether the calibration is made for 1 sigma or 2 sigma deviation. 
Calibrated date: "the caribou bone dated to cal. AD 1315 to 1345 (calibrated at 1 sigma using CALIB 3.0.3 [Stuiver and Reimer 1993]).”

\section{Other Numbers}

Page numbers: pp. 272-279 (not 272-79)

Time of day: 3:00 p.m.; noon

Age: Three-year-old; 2,000-year-old; 3,200- to 4,000-year-old.

Circa: Circa or ca. can only be used for numbers related to dates. Do not use in place of the word "about" or "around."

\section{Italics}

The use of italics for emphasis is discouraged, but if necessary use italics rather than underlining, bold, or capitalization. Indicate the use of italics by underlining or using italic font.

\section{Foreign Words or Phrases}

Italicize only those foreign words and phrases that do not occur in the main section of Webster's Collegiate Dictionary. Familiar words such as "raconteur," "per se," "eros," and "in situ" are not italicized. Foreign words and phrases should be italicized throughout the paper (exception to American Anthropologist).

When unfamiliar phrases or foreign words are first used, a bracketed note explaining their meaning should follow. If words from several languages are included in the paper, please indicate the language used within the brackets when the word is first used and defined.

Foreign words and phrases: The homestead was surrounded by a chagda (grove or forest).

Foreign words and phrases where more than one language is involved: The homestead was surrounded by a chagda (Sakha: grove or forest).

\section{Genus and Species}

The generic and specific names of plants and animals should be italicized, genus name is capitalized and species name is set in lowercase. Authors can use common names for animals throughout their text; however, it is strongly suggested that the species and genus information, if available, is used at least once in brackets behind the common name, particularly for faunal analyses.

Species: muskox is Ovibos moschatus.
Genus: a fox of a nonspecific or indeterminate species (e.g., if a bone is from either a red or arctic fox) is Vulpes sp.

\section{Legal cases.}

Use italics for the names of legal cases (e.g., Craven v. the State of Alaska).

\section{Capitalization}

Geographical and Popular Place-Names

Capitalize geographical and popular names of places. Unless usage is generally accepted (North America, North Pole), do not capitalize nonpolitical geographic areas. Do not capitalize directions.

Place-names: Baffin Island, Anchorage, the Arctic, and the Subarctic (but lowercase in adjectival use, such as "arctic fox" and "subarctic mosquitos").

Nonpolitical geographic areas: Write "northern Alaska" rather than "North Alaska" or "north Alaska;" write "eastern Arctic," "polar region," "Tanana River valley."

Words used as directions: "they moved north along the river."

\section{Names of Cultures, Complexes, and Traditions}

Capitalize the names of cultures, complexes, and traditions. Do not, however, capitalize the words "culture," "complex," or "tradition."

Cultures: "The Dorset culture is recognized for shamanic-like figurines."

Complexes: "There are controversies concerning the nature of the Norton complex."

Traditions: "The site has projectile points from the Arctic Small Tool tradition."

\section{Punctuation and Spelling}

\section{Defining specific words, terms, or phrases.}

Authors should explain how they are using certain words, terms, or phrases if they are being employed in particular ways. Such words or phrases should be set in quotation marks when first used and should be defined immediately (exception to American Anthropologist).

Defined words: "The term "Norton complex" will be used. ..."

Defined terms or phrases: "This is a form of "catch-and-release" archaeology, where artifacts are immediately reburied after excavation." 


\section{Punctuation}

Use serial commas throughout the manuscript for three or more items in a list.

Serial commas: "They hunted bearded seals, walrus, and ringed seals."

\section{Spelling}

U.S. style spelling is used in Arctic Anthropology. For instance, use "labor" rather than "labour," "practice" rather than "practise," and "theater" rather than "theatre." The Merriam-Webster's Collegiate Dictionary is used as the primary reference for spellings, with the exception of disciplinespecific terminology. Arctic Anthropology uses the Chicago Manual of Style as reference for compound modifiers (e.g., high-school student; largescale map; highly motivated speaker), and authors are encouraged to read Section 7.85 of the guide for reference.

\section{Other Spelling Conventions}

$\begin{array}{ll}\text { archaeology } & \text { microblade } \\ \text { Early Pleistocene } & \text { Paleoindian } \\ \text { endblade } & \text { pithouse } \\ \text { endscraper } & \text { seal skins } \\ \text { field notes, fieldwork, } & \text { sealskin parka } \\ \quad \text { fieldworker } & \text { sidescraper } \\ \text { fish } & \text { toolkit } \\ \text { house pit } & \end{array}$

\section{Other Matters of Style}

Authors are encouraged to consult the latest editions of The Chicago Manual of Style, which is the style guide used for the journal, as well as the American Anthropologist's style guide and Webster's Collegiate Dictionary for matters of style and spelling not included here.

\section{Acknowledgments}

Acknowledgments should follow the text and precede the "References Cited" section of the paper. Place the heading Acknowledgments in italics at the beginning of an indented paragraph. Type the acknowledgements in full sentences and doublespace the text. Please note the US spelling.

\section{References}

The accuracy of references is solely the responsibility of the author. Difficulties with references slow the editorial process and pose a burden to both editors and authors. Before submission, every manuscript should be thoroughly checked to be sure that all references cited in the text, tables, figures, and end notes are listed in the "References
Cited" section, and all listed references are actually cited in the paper. If you use a bibliographical program such as Endnote, you should be able to select the American Anthropologist style and Endnote will format in-text citations and references appropriately. However, authors are encouraged to review the references-cited section of their papers after using Endnote to compose them.

"References Cited" should begin on a new page, and the heading "References Cited" should appear centered at the top of the page. Doublespace the references and maintain the pagination established earlier in the paper. Do not autoformat a bibliographic entry with a hanging indent. Type the names of the authors on one line, followed by a hard return. On the second line of an entry type the date of the publication, tab in one stop (0.5) and begin typing the particulars of the reference without adding any hard returns within the entry. Do not use spaces to separate the date from the start of the title of the reference. The tab key (0.5) can then be used to align the entire entry after it is typed, or you may leave it aligned flush left. Entries formatted this way can be easily reformatted and corrected by the technical editor.

\section{Interviews}

An interview can be listed in the "References Cited" section under the name or pseudonym of the informant if, and only if, the interview is on file in an official repository and available to other researchers. Such citations should include, when possible, tape or transcript number, name of source, interviewer's name, name of any translator or interpreter, collection name and repository name, location of repository, grant or project title, and date of interview. If the interview is only in the possession of the author, it should be cited in the text (Robert Itak, interviewed September 30, 2002), but not included in the bibliography.

\section{Author Names}

Use full author names whenever possible. Check names that appear on a number of publications for consistency of treatment. Pay special attention to names that include middle initials and hyphenated or multipart names (e.g., Robert A. Bartlett; Ann Fienup-Riordan; George Palmer Putnam).

\section{Unpublished Conference Papers}

The use of unpublished papers presented at conferences is discouraged. If there is a compelling reason to use them, they should be cited in the bibliography. In addition to the name of the author(s) and title of the paper, the name, date, and location of the conference should be provided. 
Instead of a date, the in-text citation and date listed in "References Cited" should read "n.d."

\section{Foreign Publications.}

Check spelling and capitalization carefully. The conventions of capitalization are retained in foreign titles. Name of the place of publication may be anglicized, but the name of the publisher should not be changed.

\section{Sample Citation Formats}

\begin{tabular}{|c|c|}
\hline \\
\hline $\begin{array}{l}\text { Singl } \\
\text { Cond }\end{array}$ & $\begin{array}{l}\text { Author Book } \\
\text {, Richard G. }\end{array}$ \\
\hline 1987 & $\begin{array}{l}\text { Inuit Youth: Growth and Change in the Cana- } \\
\text { dian Arctic. New Brunswick: Rutgers University } \\
\text { Press. }\end{array}$ \\
\hline
\end{tabular}

\section{Coauthored Book}

Meade, Marie and Ann Fienup-Riordan

1996 Agayuliyararput, Kegginaqut, Kangiit-llu: Our Way of Making Prayer, Yup'ik Masks and the Stories They Tell. Seattle: University of Washington Press.

Victor, Paul-Émile and Joëlle Robert-Lamblin

1993 La civilisation du phoque. Bayonne: Raymond Chabaud.

Book with Three or More Authors

James, Clayton A., Janice H. Pine, Knud Konig, and

Lillian R. Prescott

1992 Whales and Their Kin. Chicago: Bayling Press.

\section{Author as Editor}

MacClancy, Jeremy (ed.)

1997 Contesting Art: Art, Politics and Identity in the Modern World. New York: Berg.

\section{Book in a Series}

Fitzhugh, William W.

1972 Environmental Archeology and Cultural Systems in Hamilton Inlet, Labrador. Smithsonian Contributions to Anthropology, 16. Washington, D.C.: Smithsonian Institution Press.

\section{One Volume in a Multivolume Work}

Oosten, Jarich and Laugrand, Frédéric (ed.)

1999 The Transition to Christianity. vol. 1. Inuit Perspectives on the Twentieth Century. Iqaluit: Arctic College/Nortext.

\section{Chapter in a Book with Editor(s)}

Graburn, Nelson H.H.

1980 Man, Beast, and Transformation in Canadian Inuit Art and Culture. In Manlike Monsters on Trial: Early Records and Modern Evidence. Marjorie M. Halpin and Michael M. Ames, eds.
Pp. 193-210. Vancouver: University of British Columbia Press.

Rogers, Edward S.

1981 History of Ethnological Research in the Subarctic Shield and Mackenzie Borderlands. In Handbook of North American Indians. vol. 6. Subarctic. June Helm, ed. Pp. 19-29. Washington, D.C.: Smithsonian Institution Press.

\section{Reprint}

Boas, Franz

[1888] The Central Eskimo. Lincoln: University of 1964 Nebraska Press.

\section{Translation}

Billotti, Vera

2001 Italian Ethnographers in the Far North. Jeanette Ransom, trans. Salem: Mallard Press.

Foreign with Translated Text

Zhuravlev, Semen Maksimovich

1967 Along the New Path. In Elgeeii sovsovkhoz (Elgeeii State Farm). N.F. Sleptsov, ed. Pp. 1-8. Yakutsk: Yakutknigoizdat.

\section{Articles}

\section{Article in Journal}

Harper, Kenn

1985 The Early Development of Inuktitut Syllabic Orthography. Études/ Inuit/Studies 9(1): 141-162.

\section{Article in Journal Theme Issue}

Quinn, Carlita

1995 Elmo Falling: Recording Childhood Dreams. In Dream Studies across Time, Age, and Culture. Theme issue. Oneirae 24(2):188-199.

\section{Material in Archives}

Peck Papers

n.d. M56-1. General Synod Archives of the Anglican Church of Canada, Toronto.

\section{Report}

Northern Power and Light

1988 Line Survey Results, 1987-88. Inter-office Report, 52. Fantail, Alaska: Northern Power and Light Corporation.

\section{Ph.D. dissertation or M.A. Thesis}

Loring, Stephen

1992 Princes and Princesses of Ragged Fame: Innu Archaeology and Ethnohistory in Labrador. Ph.D. dissertation, Department of Anthropology, University of Massachusetts. 


\section{Internet Documents}

Citation of internet documents should be avoided since they are subject to change. However, when such citation is unavoidable be sure to review the web site and identify the person, research group, and/or repository that authored or released the information. For FTP or Telnet sites begin URL with (ftp:// . . ), for WWW sites begin with (http:// . .), and for gopher sites use (gopher:// ...).

Rast, Tim

2013 Plans and Profiles \#15. Frédéric Dussault, Archaeoentomology on Dorset Palaeoeskimo sites in Newfoundland. http://elfshotgallery.blogspot.com/2013/04/plans-and-profiles-fredericdussault.html.

\section{Multiple References in the Same Year}

Citation of works published by an author in the same year should be organized alphabetically by title and identified with letters appended to publication date:

Schledermann, Peter

1976a The Effect of Climatic/Ecological Changes on the Style of Thule Culture Winter Dwellings. Arctic and Alpine Research 8:36-47.

1976b Thule Culture Communal Houses in Labrador. Arctic 29:27-37.

\section{Multiple References that Include an Edited Volume}

An edited volume published in the same year as another publication by the same author should be cited as follows:

McCartney, Allen P.

1995 Whale Size Selection by Precontact Hunters of the North American Western Arctic and Subarctic. In Hunting the Largest Animals: Native Whaling in the Western Arctic and Subarctic. Allen P. McCartney, ed. Pp. 83-108. Studies in Whaling, No. 3, Occasional Publication No. 36. Alberta: The Canadian Circumpolar Institute.

McCartney, Allen P. (ed.)

1995 Hunting the Largest Animals: Native Whaling in the Western Arctic and Subarctic. Studies in Whaling, No. 3, Occasional Publication No. 36. Alberta: The Canadian Circumpolar Institute.

\section{Work Accepted for Publication}

Works accepted for publication can be cited in the manuscript and should be listed in the bibliography. Please remember that a work in preparation or submitted but not accepted for publication cannot be cited as its ultimate title, and date and place of publication can change.

Beershon, Vance R.

in press Northern Placenames: Cultural Imperialism and Naming Traditions. Boise: Swank and Peters.

\section{Unpublished Conference Paper (Discouraged)}

Jordan, Richard $\mathrm{H}$.

n.d. Archaeological Investigations of the Hamilton Inlet Labrador Eskimo: Social and Economic Responses to European Contact. Paper presented at the 75th Annual meeting of the American Anthropological Association, Washington, D.C. November 1976.

\section{Multiple n.d. Entries}

Occasionally, an author will have multiple n.d. citations through a combination of conference papers and archival material. In such cases, the work will be listed as n.d.[year of creation]. For example, Burch (1972, n.d. [1998], n.d. [1999].

\section{Copyright}

If an author proposes to include an illustration that has been previously copyrighted, it is the author's responsibility to obtain written permission from the copyright holder and to pay any use fees related to the material's publication. Contributors are encouraged to consult with the editor concerning the paperwork that is required.

\section{Manuscript Submission}

Manuscripts should be submitted electronically to: cmdarwent@ucdavis.edu

Christyann M. Darwent

Editor, Arctic Anthropology

Department of Anthropology

One Shields Avenue

University of California, Davis

USA 95616-8522

Note : If your files are too large to be transmitted using conventional email, please contact the editor for alternate methods of electronic transfer. 